\section{Hemangioendotelioma epitelioide. Presentación de un caso diagnosticado a partir de lesión cutánea}

\section{Sr. Director:}

El hemangioendotelioma epitelioide (HEE) es un tumor poco frecuente, de etiología desconocida de origen vascular y de malignidad intermedia. Fue descrito por Weiss y Enzinger en 1982 (1). Suele presentarse en adultos menores de 40 años la mayoría de las veces asintomáticos constituyendo un hallazgo radiológico fortuito en el $50 \%$ de los casos.

Presentamos el caso de un varón de 33 años diagnosticado de HEE a partir de una lesión cutánea que fue remitido a la consulta de Medicina Interna porque en unos análisis rutinarios presentaba una histolisis hepática y una ecografía mostraba múltiples LOES en el hígado. El paciente estaba asintomático y no tenía síndrome constitucional ni hábitos tóxicos. Los exámenes complementarios fueron: análisis GPT 86 U/L, GGT 73 U/L, F.A. 188 U/L, LDH $254 \mathrm{U} / \mathrm{L}$, creatinina $1 \mathrm{mg} / \mathrm{dL}$, PSA, Beta HCG, Ca 19,9 y AFP normales. Rx de tórax con múltiples nódulos pulmonares bilaterales de $5 \mathrm{~mm}$ mal definidos. Ecografía abdominal con múltiples LOES hepáticas de hasta 2,5 cm de diámetro. Ecografía testicular normal. Ecografía cervical: adenopatías cervicales significativas submandibulares bilaterales y en cadena yugular interna izquierda. TAC toraco-abdominal: múltiples nódulos parenquimatosos de 1 a $8 \mathrm{~mm}$ sugestivos de metástasis a nivel pulmonar y múltiples LOES hepáticas de entre 0,5 y $2,5 \mathrm{~cm}$ compatibles con metástasis. El examen minucioso de la piel permitió descubrir que tenía una lesión granular en la región parietal izquierda de $1,5 \mathrm{~cm}$ de coloración marrón oscura que sangraba al roce cicatrizando posteriormente por la que nunca había consultado. Por este motivo se decidió tomar biopsia de dicha lesión cutánea cuyo diagnóstico anatomopatológico fue hemangioendotelioma epitelioide.

La descripción microscópica de la lesión era la siguiente: histológicamente se observa a nivel de la dermis una proliferación neoplásica de células poligonales o redondas de abundante citoplasma eosinófilo con vacuolas y núcleos grandes, vesiculosos, con nucléolo prominente. La actividad mitósica es escasa. Las células tienen un hábito epitelioide, se tiñen con marcadores vasculares (factor VIII y CD 34) y se disponen en nidos y cordones. Se reconoce la existencia de una vena en el seno de la masa tumoral de donde parece originarse el tumor con una extensión aparentemente centrífuga quedando la luz llena de una mezcla de tumor, detritus y colágeno denso. En superficie el tumor se hallaba ulcerado y recubierto de una escara fibronecrótica.

El HEE es un tumor angiocéntrico, derivado de las células endoteliales, que muestran un aspecto epitelioide, caracterizadas por su forma redondeada o poligonal con abundante citoplasma eosinófilo y presencia de pequeñas luces intracelulares que ocasionalmente contienen eritrocitos. Con microscopia electrónica muestra características de endotelio y se pueden encontrar cuerpos de Weibel-Palade en el citoplasma. La mayoría de los tumores presentan escasa actividad mitótica pero algunos muestran leve atipia o mas de una mitósis/10 CGA, hechos que están asociados a peor pronóstico. El tumor llena la luz del vaso y expande hacia la pared de forma centrífuga destruyendo parcialmente la túnica elástica y la muscular. Los marcadores tumorales sensibles para neoplasias vasculares son: factor VIII, antígeno CD 34 y ulex europeus. EI factor VIII tiene un grado de positividad del $97,5 \%$ siendo mas acentuada alrededor de las microluces intracitoplasmáticas. El antígeno CD 34 deriva de progenitores hematopoyéticos y es un buen marcador de las células endoteliales.

Son tumores relativamente pequeños, circunscritos, localizados en hígado, pulmón, piel (1) y partes blandas (2). Se originan en un vaso de mediano tamaño o una vena grande. Dada la agresividad intermedia que tienen estos tumores, muchos pacientes están asintomáticos hasta fases avanzadas de la enfermedad presentando disnea, hemoptisis, ictericia obstructiva, dolor abdominal y síndrome constitucional.

En la Rx y TAC de tórax pueden presentarse como múltiples nódulos mal definidos, un nódulo solitario o un patrón intersticial. En la ecografía y el TAC hepático presentan múltiples LOES. Los análisis pueden mostrar elevación de la fosfatasa alcalina y citolisis como en nuestro caso.

El diagnóstico diferencial se plantea principalmente con un carcinoma metastático (cáncer de pulmón, mama, tiroides, glándulas salivares, testículo o de origen desconocido). Otros diagnósticos posibles son angiosarcoma, sarcoma de Kaposi, liposarcoma, sarcoma epitelioide, condrosarcoma mixoide, hiperplasia angiolinfoide, enfermedad de Kimura y granuloma seudopiogénico.

Se ha debatido mucho el carácter multicéntrico o metastático del HEE, es decir si las lesiones halladas en múltiples órganos son metastásicas o multifocales con carácter primario en cada uno de ellos. Los estudios de Nerlich y cols. (3) basados en la 
diferente composición de la membrana basal de pulmón e hígado apoyan según estos autores su carácter multicéntrico y no metastásico. En nuestro caso cuando se descubrió la lesión cutánea ya tenía lesiones concomitantes en hígado y pulmón.

En cuanto al pronóstico y tratamiento del HEE hay que decir que suelen presentar un curso lento con crecimiento progresivo y aparición de nuevas lesiones pero no metastatizan. Tienen una supervivencia media de 20 años. Otros casos llevan a una muerte rápida por hipertensión pulmonar, hemorragia alveolar, insuficiencia respiratoria o hepatocelular. La malignidad intermedia de estos tumores hace difícil recomendar un tratamiento quimioterápico definido y apenas hay referencias en la literatura. En nuestro caso se optó por realizar un tratamiento con carboplatino-etopósido con nula respuesta. Un año después del diagnóstico el paciente permanece asintomático. Cuando se localiza en piel y tejidos blandos se recomienda la excisión. Cuando se localiza en hígado se han realizado transplantes con resultados similares a otros transplantes.

La presentación clínica de nuestro caso, con una lesión cutánea asociada a lesiones multicéntricas en hígado y pulmón es excepcional. La gran mayoría de los casos se manifiestan como lesiones hepáticas y pulmonares o en partes blandas y la afectación cutánea se ha descrito de forma aislada pero rara vez se asocia con las anteriores (4).

También creemos que nuestro caso pone de manifiesto la importancia que tiene para el clínico el realizar una exploración minuciosa del paciente buscando en la piel posibles lesiones ocultas, incluyendo el cuero cabelludo y por la que el paciente no había consultado y que nos permitió hacer el diagnóstico de HEE. La revisión de la literatura revela la malignidad intermedia de este tumor que deriva en una larga supervivencia lo que parece estar mas en relación con la multifocalidad de estos tumores que con el supuesto carácter metastásico.

\section{A. Ramírez Herrero, I. Serrano Martín', C. de Blas Gar- cía $^{2}$, E. Lastra Aras ${ }^{3}$}

Servicios de Medicina Interna $y^{I}$ Anatomía Patológica. Hospital Santos Reyes. ${ }^{2}$ MFC. Centro de Salud Aranda Norte. Aranda de Duero. ${ }^{3}$ Servicio de Ontología. Hospital General Yagüe. Burgos

1. Quante M. Patel NK, Hill S, et al. Epithelioid hemangioendothelioma presenting in skin: a clinicopathologic study of eight cases. Am J D Dermatophatol 1998; 20: 541 .

2. Vázquez M, Ordóñez NG, English GW, Mackay B. Epithelioid hemangioendothelioma of soft tissue: report of a case with ultrastructural observations. Ultrastruct Pathol 1998; 22: 73.

3. Nerlich A, Berndt R, Schleicher E. Differential basement membrane composition in multiple epithelioid haemangioendothelioma. A previosly unreported manifestation of a rare tumor. Am Rev Respir Dis 1990; 142: 700-1.

4. Mentzl T, Beham A, Calonje E, Katemkamp D, Fletcher CD, Epithelioid hemangioendothelioma of skin and soft tissues: clinicopathologic and inmunohistochemical study of 30 cases. Am J Surg Pathol 1997; 21: 363-74.

\section{Crioglobulinemia mixta asociada a infección de catéter ventrículoatrial}

\section{Sr. Director:}

La crioglobulinemia mixta (tipo I y II) se asocia a enfermedades autoinmunes, síndromes linfoproliferativos, enfermedades del tejido conectivo o infecciones crónicas. La asociación de crioglobulinas a enfermedades infecciosas, especialmente al virus de la hepatitis C (VHC) (1), es bien conocida. También se han documentado casos secundarios a otras infecciones $(2,3)$. Comunicamos un caso ilustrativo de crioglobulinemia mixta tipo II asociada a infección de la derivación ventrículo atrial por $S$. epidermidis.

Mujer de 34 años, portadora de una derivación ventrículoatrial (DVA) desde hacía 10 años por hidrocefalia secundaria a estenosis del acueducto de Silvio, fue remitida a las consultas externas de Medicina Interna para estudio de anemia de enfermedad crónica. En la anamnesis por aparatos no destacaba ningún dato de interés y la exploración física fue normal. Los datos analíticos revelaron una hemoglobina $11,3 \mathrm{~g} / \mathrm{dL}$, VCM $80 \mathrm{fL}$, VSG $83 \mathrm{~mm}$ en la primera hora, PCR 31,9 mg/L, proteínas totales $9,38 \mathrm{~g} / \mathrm{dL}$, proteinograma con aumento policlonal de las inmunoglobulinas, IgG 3023, IgM 304 con Ig A normal; resto normal. Factor reumatoide (FR): 165 $\mathrm{UI} / \mathrm{ml}$ (VN: 0-14). C3: 51, C4<2. La determinación de crioglobulinas fue positiva para el tipo 2 IgG policlonal-IgM monoclonal, compatible con crioglobulinemia mixta tipo 2. En el sedimento de orina se detectaron 20-30 hematíes por campo. Proteinuria: 861 $\mathrm{mg} / 24$ horas, aclaramiento de creatinina: $65,39 \mathrm{~mL} /$ minuto. La serología frente a sífilis, citomegalovirus, Brucella, virus de hepatitis C y B y VIH fue negativa. Tres cultivos de esputo y dos cultivos de orina en medio de Löwenstein fueron negativos. El aspirado de médula ósea mostró una plasmocitosis reactiva, y el cultivo en medio NNN para Leishmania fue negativo. La TC toracoabdominal no mostró alteraciones, y la TC craneal reveló dilatación de los ventrículos y la derivación localizada dentro del sistema ventricular. En la ecocardiografía se apreciaba el catéter en la aurícula derecha, y un corazón estructuralmente normal. La paciente fue controlada en consultas externas, continuó asintomática y durante el seguimiento ambulatorio, cuatro meses después de la primera consulta, ingresó en Neurocirugía por obstrucción de la derivación ventrículo atrial. Se le solicitó 6 hemocultivos, a pesar de que permanecía afebril, y en todos ellos se aisló $S$. epidermidis sensible a oxacilina. Se realizó una segunda ecocardiografía, y en ella, se apreciaba una imagen filiforme, móvil, menor de 2 centímetros en la punta del catéter, compatible con una verruga. Se inició tratamiento antibiótico (vancomicina más rifampicina intravenosas) y se retiró la DVA.

La crioglobulinemia es una forma especial de vasculitis sistémica, englobada en el subgrupo de vasculitis mediadas por complejos inmunes. Sus manifestaciones clínicas oscilan desde formas asintomática u oligosintomáticas, con púrpura palpable, artralgias y fatiga, hasta una forma grave de vasculitis, con necrosis cutánea, afectación renal, afectación de los nervios periféricos, del sistema nervioso central, del aparato respiratorio, del miocardio y/o del tracto gastrointestinal. Lo más frecuente es que aparezcan síntomas y signos debidos al cuadro séptico, de intensidad variable, seguido de la afectación renal, que puede ocurrir hasta en el 50\% de los casos, y que es la manifestación inicial en un $5,9 \%$ de los mismos (4).

La nefritis, como complicación de la infección del shunt ventrículo atrial, fue descrita por primera vez en 1965, por Black y cols. y denominada nefritis por shunt (5). La incidencia de la infección del shunt es de aproximadamente un 14\%, y entre un 0,7 y un $2,25 \%$ de los pacientes con una derivación infectada pueden presentar esta enfermedad. Habitualmente transcurre un largo intervalo de tiempo entre la colocación del shunt y la aparición de los síntomas, con una media de aproximada de 3 años, y el inicio suele ser insidioso, lo que puede retrasar el diagnóstico; en estos casos, sólo un alto índice de sospecha puede llevar al diagnóstico $(6,7)$. Desde el punto de vista clínico, la hematuria es la manifestación más frecuente $(89 \%)$, seguida por la fiebre $(88 \%)$, anemia $(86 \%)$ y proteinuria $(70 \%)(8)$. La etiología suele ser infecciosa (microorganismos de baja virulencia) y hasta en el $70 \%$ de los casos se aísla S. epidermidis (6).

Los hallazgos característicos de laboratorio son la anemia ferropénica o anemia normocítica normocrómica moderada, la proteinuria y la hematuria microscópica (4). Las alteraciones de 
la función renal oscilan entre una azoemia media con oliguria temporal, hasta incluso anuria.

Esta enfermedad se produce como resultado de la formación de complejos inmunes con los antígenos bacterianos y la activación de la vía clásica del complemento, con el posterior depósito en el glomérulo renal (9).

El tratamiento requiere la administración de antibióticos y la retirada de la derivación infectada y la evolución clínica suele ser favorable (9).

Esta paciente era portadora de una derivación ventrículo atrial desde hacía 10 años, la presentación clínica fue tardía e insidiosa, estaba afebril y asintomática, y sólo las alteraciones analíticas, en especial, el descenso de la fracción 4 del complemento, y la alteración del sedimento de orina en una paciente portadora de una DVA, nos orientaron al diagnóstico. La presencia de crioglobulinas fue clave en la orientación diagnóstica y precedió a las manifestaciones de la infección del shunt ventrículo atrial. Las crioglobulinas pueden, por tanto, ser un marcador analítico útil y temprano para predecir la infección de la derivación ventrículo atrial, como ocurrió en este caso.

\section{J. Molina Garrido, A. Mora Rufete, G. Penadés Cervera, R. Enríquez Escarza' ${ }^{1}$ C. M. Escolano Hortelano}

Servicio de Medicina Interna. Sección Oncología médica. ${ }^{\text {SSec- }}$ ción Nefrología. Hospital General Universitario. Elche

1. Mazzaro C, Panarello G, Tesio F, Santini G. Hepatitis C virus risk: a hepatitis C virus related syndrome. J Intern Med 2000; 247: 535-45.

2. Roca JM, García-Bragado F et al. Cryoglobulinemia in the course of infectious diseases. Rev Clin Esp 1981; 163 (1): 29-31.

3. Kordosis T, Sipsas NV, Kontos A, Dafni U, Moutsopoulos HM. Mixed cryoglobulinemia is associated with increased risk for death, or neoplasia in HIV-1 infection. Eur J Clin Invest 2001; 31: 1078-82.

4. Duong JP, Nochy D. Cryoglobulinemia. Arch Anat Cytol Pathol 1996; 44: $106-8$.

5. Csoma M, Coppens L, Farber CM, Achslogh J, Lustman F. Shunt nephritis in an adult: apropos of a case. Acta Clin Belg 1980; 35 (2): 71-5.

6. Kubota M, Sakata Y, Saeki N, Yanaura A, Ogawa M. A case of shunt nephritis diagnosed 17 years after ventriculoatrial shunt implantation. Clin Neurol Neurosurg 2001; 103: 245-6.

7. Vernet O, Rilliet B. Late complications of ventriculoatrial or ventriculoperitoneal shunts. Lancet 2001; 358: 1569-70.

8. Blanche P, Sicard D. Leukocytoclastic vasculitis related to cryoglobulinemia, satellite to staphylococcal infection. Presse Med 1995; 24 (10): 504.

9. Rieou V, Cohen P, André MH, Mouthon L, et al. Characteristics and outcome of 49 patients with symptomatic cryoglobulinemia. Rheumatology 2002; 41: 290-300.

\section{Infección respiratoria por Kluyvera $s p$, ¿responsable o consecuencia?}

\section{Sr. Director:}

Presentamos el caso de una sobreinfección respiratoria por la especie Kluyvera del género ascorbata por ser éste un germen poco aislado en este tipo de infecciones.

Paciente de 85 años con antecedentes de EPOC (enfermedad pulmonar obstructiva crónica), estenosis aórtica intervenida (protesis biológica) y prostatismo, que ingresa en medicina interna por cuadro de disnea, siendo diagnosticado de insuficiencia cardiaca izda. e infección del tracto urinario por Pseudomonas sp. También durante el ingreso, el paciente desarrolla un cuadro de infección respiraroria con abundantes secreciones y sin clara condensación, por Staphylococcus aureus meticilin resistente (SARM). Analítica: Hb 130 g/l; Hto: 40,1\%; leucocitos 15,9 por 109 (N: 80\%; L: 10\%; M: 9,8\%); bioquímica: glucosa: $106 \mathrm{mg} / \mathrm{dl}$; urea: $51 \mathrm{mg} / \mathrm{dl}$; creatinina $1,2 \mathrm{mg} / \mathrm{dl} ; \mathrm{Na}: 141$ $\mathrm{mmol} / \mathrm{L}$; K: $4 \mathrm{mmol} / \mathrm{L}$; ALT: $16 \mathrm{U} / \mathrm{L}$; colesterol: $123 \mathrm{mg} / \mathrm{dl}$; CK: $58 \mathrm{U} / \mathrm{L}$.

Al paciente se le instaura tratamiento con vancomicina y posteriormente con cotrimoxazol a dosis habituales con escasa mejoría del cuadro respiratorio persistiendo abundantes secreciones. Se le practican dos cultivos de esputo con el intervalo de una semana y en el último, el paciente presenta crecimiento de bacilo gram negativo que tras la identificación se clasifica como Kluyvera ascorbata (sensible a: cefazolina, cefotaxima, amikacina, imipenem y cefuroxima; resistente a: ampicilina, SXT, gentamicina, ciprofloxacino, tobramicina). Tras instaurar tratamiento con imipenem $500 \mathrm{mg} / 8 \mathrm{~h}$ i.v., el paciente presenta buena evolución de la clínica respiratoria, con mejoría de su disnea y disminución de secreciones purulentas respiratorias.

La infección por el género Kluyvera ha sido poco descrita, siendo éste un germen gram negativo flagelado, del que destacan fundamentalmente dos generos: $K$. ascorbata y $K$. cryocrensces $(1,2)$. Inicialmente se consideró un comensal de las vías aéreas superiores y del tracto gastrointestinal (1). Sin embargo, desde hace unos quince años, se ha implicado como un verdadero patógeno en una serie de casos diferentes, incluyendo bacteremia (3), sepsis severa (4); también ha sido descrita en bacteriemias en relación con fracturas abiertas (2), peritonitis (5), colecistitis agudas $(6,7)$, e incluso como causante de meningitis en un paciente con derivación lumbo peritoneal (8).

Es difícil correlacionar las infecciones por la especie Kluyvera con características clínicas específicas. Los aislamientos iniciales de muestras del tracto respiratorio fueron probablemente más debido a colonización que a infección (4), aunque hay descrito un caso de mediastinitis por Kluyvera en el que parece claro el origen respiratorio de dicha infección (9); siendo rara la infección respiratoria pura en pacientes inmunocompetentes.

Nuestro caso nos parece interesante, debido a que si el germen inicialmente pudiese ser un comensal de vías respiratorias, tras el tratamiento con antibióticos de amplio espectro (por SARM), se produce una infección respiratoria clinicamente significativa que cursa fundamentalemente con un aumento de secreciones respiratorias, y fiebre que se resuelve con tratamiento antibiótico específico.

Como conclusión podemos decir que el tratamiento de infecciones con antibióticos de amplio espectro puede seleccionar cepas de Kluyvera que produzacan infecciones clinicamente significativas y como en nuestro caso, infección respiratoria y por todo ello debemos ser prudentes en el uso de antibioterapia de amplio espectro en personas de edad avanzada.

\section{J. Oteiza, G. Tiberio ${ }^{1}$, A. Meléndez, J. Viguria}

Servicio de Medicina Interna y Paliativos. Hospital S. Juan de Dios. ${ }^{I}$ Servicio de Medicina Interna. Hospital Virgen del Camino. Pamplona

1. Farmer JJ III, Fanning GR, Huntley-Carter GP, Holmes B, Hickman FW, Richard C, et al. Kluyvera, a new (redefined) genus in the family Enterobacteriaceae: identificacion of Kluyvera ascorbata sp nov and Kluyvera cryocrescens sp nov in clinical specimens. J Clin Microbiol 1981; 13: 919-33.

2. Gil d de M, Navarrete CM; Lizama V, et al. bacteremia caused by Kluyvera cryocrescens: report of two cases. Rev Chil Infectol 2001; 18: 72 74. ISSN 0716-1018.

3. Padilla E, Tudela P, Giménez M, Gimeno JM. Bacteremia por Kluyvera ascorbata. Med Clin (Barc) 1997; 108: 479 
4. Sanchis V, Sánchez R, Marcaida G, Llucían R. Infecciones por Kluyvera ascorbata. A propósito de dos casos. Rev Clin Esp 1992; 190: 187-8.

5. Sezer M, Gultekin M, Gunseren F, erkilic m, Ersoy F. A case of Kluyvera cryocrescens peritonitis in a CAPD patient. Perit Dial Int 1996; 16: 326-7.

6. Thaller R, Berlutti F, Thaller M. A Kluyvera cryocrescens strain from a gallbladder infection. Eur J Epidemiol 1998; 4:124-6.

7. Batista N, Díez O, Moreno A, Ode J. Colecistitis aguda por Kluyvera ascorbata. Enferm Infecc Microbiol Clin 2002; 20: 370-1

8. Paredes-Rodríguez D, Villalobos-Vindas J, Avilés-Montoya A, Alvarado-Cerdas E. Meningitis por Kluyvera sp. en una paciente con una derivación lumbo-peritoneal: reporte de un caso. Acta Médica Costarricense 2002; 44: 126-7.

9. Sierra- Madero J, Pratt K, Hall GS, Stewart RW, et al. Kluyvera mediastinitis following open-heart surgery: a case report. Clin Microbiol 1990; 28 (12): 2848-9.

\section{Varón con fiebre y artritis}

\section{Sr Director:}

La presencia de artralgias en la fiebre Q es un hecho habitual pero la existencia de artritis franca es inusual y ha sido escasamente documentada en la literatura $(1,2)$. Presentamos el caso de un varón con oligoartritis por fiebre $\mathrm{Q}$.

Varón de 45 años, fumador de 20 cigarrillos/día y bebedor moderado, procedente del medio rural, que consultó por un cuadro febril y malestar general da 10 días de evolución, junto a tumefacción dolorosa progresiva de ambos tobillos y muñeca izquierda de 5 días de evolución. Refería un cuadro de características similares un mes antes, con fiebre de hasta $39^{\circ} \mathrm{C}$ con tiritona, escalofríos, sudoración y artromialgias generalizadas, por lo que se realizó una analítica general donde se evidenció una hipertransaminemia leve (GOT 72 U/L, GPT 75 U/L, bilirrubina y fosfatasa alcalina normales) con hemograma normal, y radiografía de tórax y abdomen sin alteraciones. El cuadro cedió espontáneamente sin tratamiento. En esta ocasión, a la exploración se encontraba normotenso y afebril, con buen estado general y correctamente nutrido e hidratado, con auscultación cardiopulmonar normal, abdomen sin hallazgos patológicos y no se palpaban adenopatías periféricas. Si destacaban signos inflamatorios en ambos tobillos y muñeca izquierda, sin otra focalidad infecciosa. Las determinaciones de laboratorio mostraron: leucocitos $23,8 \times 10 \%$ ( $76 \%$ neutrófilos, $15 \%$ linfocitos), hemoglobina $12,6 \mathrm{mg} / \mathrm{dl}$, hematocrito $37 \%$, y $345 \times 10^{9} / 1$ plaquetas. En la bioquímica presentó: GOT 16 U/l, GPT 11U/l, GGT 17 $\mathrm{U} / \mathrm{l}$ y bilirrubina total $0,45 \mathrm{mg} / \mathrm{dl}$, y la función renal e iones fueron normales. La PCR era 14,6 mg/dl, VSG $103 \mathrm{~mm} / 1^{\text {a }}$ hora, y ASLO 1.530. El sedimento de orina, la Rx de tórax y electrocardiograma no presentaban alteraciones. Y los urocultivos y hemocultivos resultaron negativos. Se realizó el diagnóstico de presunción de fiebre reumática en base a la existencia de criterios diagnósticos (artritis, fiebre y elevación de VSG y PCR, leucocitosis y elevación de ASLO) y se inició tratamiento con penicilina benzatina a dosis de 1.200.000 UI im e indometacina. A los siete días del ingreso se recibió la serología para Brucella, Borrelia burdogferi, Rickettsia conorii, VEB, CMV, VIH y virus de hepatitis B y C que fueron negativos, y una serología positiva para Coxiella burnetti, mediante IFI (VIRCEL, SL Granada) con Ig M positiva e Ig G 1/1.024. Ante el diagnóstico de oligoartritis en el contexto de fiebre $\mathrm{Q}$ aguda se inició tratamiento con Doxiciclina y antiinflamatorios, que se mantuvo durante 21 días con buena evolución clínica. Previo al alta a domicilio se realizó una ecocardiografía transtorácica que descartó la afectación endocárdica por Coxiella. Cuatro semanas después del alta la Ig M para Coxiella fue negativa.
La fiebre $\mathrm{Q}$ es una zoonosis de distribución mundial y frecuente en España causada por Coxiella burnetti. El espectro clínico abarca desde la infección subclínica hasta cuadros graves, incluso mortales (1). Las formas clínicas más frecuentes de presentación aguda son el síndrome febril aislado, la hepatitis y la neumonía, y menos frecuentes pericarditis o miocarditis, y meningitis aséptica o encefalitis. La fiebre Q crónica se puede manifestar de diferentes formas, la más frecuente y grave la endocarditis; y otras son la hepatitis granulomatosa, la enfermedad pulmonar intersticial o la glomerulonefritis $(2,3)$. La afectación osteoarticular en forma de osteomielitis, coxitis, espondilodiscitis o artritis ha sido descrita en casos de infección crónica por Coxiella burnetti, aunque en una baja proporción, entre un $0,5 \%$ y un $3,5 \%$ según las series estudiadas $(4,5)$. En una serie de 40 pacientes con fiebre Q aguda estudiados en la zona sur de la isla de Gran Canarias se dieron 2,5\% de casos con artritis, sin embargo, como bien dice el autor el grado de sospecha clínica en esa zona geográfica es elevado por la considerable incidencia de la enfermedad, con lo cual el diagnóstico es mayor (2). No hemos encontrado publicado en la bibliografía revisada ningún caso de oligoartritis en el contexto de fiebre Q aguda en nuestro medio, pero la presentación aguda inespecífica, de curso autolimitado, y la necesidad de pruebas serológicas para su diagnóstico, hacen que sea una enfermedad infradiagnosticada. Queremos destacar la necesidad de descartar la infección aguda por Coxiella ante un caso de oligoartritis, porque aunque la clínica pueda ceder espontáneamente es importante evitar la persistencia la infección crónica con tratamiento antibiótico adecuado.

\section{J. Aguilar García, J. de la Torre Lima, J. L. Prada Pardal,} A. del Arco Jiménez

Servicio de Medicina Interna. Hospital Costa del Sol. Marbella (Málaga)

1. Maurin M, Raoult D. Q Fever. Clin Microbiol Rev 1999; 12: 518-53.

2. Bolaños M, Santana OE, Pérez-Arellano JL, Ángel-Moreno A, Moreno G. Fiebre Q en Gran Canarias. Aportación de 40 nuevos casos. Enferm Infecc Microbiol Clin 2003; 21 (1): 20-23

3. Heredero E, Martín A, Lorente S, Bartolomé J. Fiebre Q y miocarditis. Enferm Infecc Microbiol Clin 2003; 21 (7): 383-385

4. Raoult D, Tissot-Dupont H, Foucault C, Gouvernet J, Fournier P, Bernit E, Stein A, Nesri M, Harle JR, Welleir PJ. Q fever 1985-1998. Clinical and epidemiologic features of 1.383 infections. Medicine (Baltimore) 2000; 79: 109-123.

5. Brouqui P, Dupont HP, Drancourt M, Berland Y, Etienne J, Leport C, Goldstein F, Massip P, Micoud M, Bertrand A, et al. Chronic Q fever. Ninety-two cases from France, including 27 cases without endocarditis. Arch Intern Med 1993; 153 (5): 642-648.

\section{Endocarditis sobre válvula pulmonar nativa por Enterococcus faecalis}

\section{Sr Director:}

La endocarditis infecciosa asienta preferentemente en cavidades izquierdas. La endocarditis derecha representa menos del 7\% de los casos y suele afectar a la válvula tricúspidea (1). La endocarditis sobre válvula pulmonar es menos frecuente, representando menos de $1,5 \%$ de los casos de endocarditis (2). Se presenta un caso de endocarditis sobre válvula pulmonar en paciente recientemente diagnosticado de neoplasia de colon. 
Varón de 73 años de origen inglés y residente en nuestro área sanitaria, que consulta por fiebre de hasta $40{ }^{\circ} \mathrm{C}$ y escalofríos sin foco aparente de 10 días de evolución. El paciente había sido intervenido en otro centro mediante hemicolectomía izquierda por adenocarcinoma de colon T4N0M0 dos meses antes. El resto de los antecedentes patológicos carecían de interés. La exploración física al ingreso fue normal, destacando en la analítica la presencia de anemia y leucocitosis con neutrofilia, junto a una cifra de creatinina en suero de $3,2 \mathrm{mg} / \mathrm{dl}$.

Se comenzó tratamiento antibiótico empírico con levofloxacino. Tres días después se aisló Enterococcus faecalis en los cuatro hemocultivos extraídos al ingreso. El microorganismo era sensible a ampicilina (CMI $<0,5 \mathrm{mg} / \mathrm{l})$ y estreptomicina $(\mathrm{CMI}<1000 \mathrm{mg} / \mathrm{L})$ y resistente a gentamicina $(\mathrm{CMI}>500$ $\mathrm{mg} / \mathrm{L}$ ). Fue entonces cuando se procedió al cambio de tratamiento antibiótico por ampicilina asociada a estreptomicina ajustada a función renal, quedando el paciente afebril 24 horas después. Posteriormente se practicó ecocardiografía transtorácica que no fue concluyente por mala ventana pulmonar, por lo que se realizó ecocardiografía transesofágica en la que se objetivó una vegetación móvil a nivel de la válvula pulmonar. En el undécimo día de ingreso el paciente presentó disnea de instauración brusca asociada a tos irritativa y dolor torácico de características pleuríticas. Tras realizar radiografía simple y tomografía computerizada torácica se constató la presencia de derrame pleural bilateral de predominio izquierdo e infiltrados parenquimatosos bilaterales así como dilatación de las arterias pulmonares, lo cual sugería la presencia de hipertensión pulmonar y embolismos pulmonares sépticos. El tratamiento antibiótico combinado se mantuvo durante ocho semanas, tiempo en el que se negativizaron los hemocultivos, se normalizó la función renal y mejoró la clínica respiratoria. A los 7 días de suspender el tratamiento reapareció la fiebre. Se cursaron nuevos hemocultivos y se reinstauró la antibioterapia con los mismos agentes. Se aisló E. faecalis en sangre y la ecocardiografía mostró la persistencia de la vegetación sobre válvula pulmonar. En las siguientes 48 horas, el paciente quedó afebril. Clínicamente estable, solicitó traslado para continuar tratamiento en su país de origen.

La endocarditis de este paciente podría haber tenido un origen nosocomial ya que había estado sondado durante la intervención quirúrgica previa. La endocarditis nosocomial es cada vez más frecuente, y puede representar el $10 \%$ del total de casos de endocarditis (3); en general esta relacionada con catéteres venosos y manipulaciones urológicas (3).

La endocarditis sobre válvula pulmonar es poco frecuente. Suele ser mixta con afectación de válvula tricuspidea $(1,4)$. Suele acontecer en el contexto de una afectación válvular congénita, prótesis o valvuloplastia pulmonar $(4,5)$. La endocarditis sobre válvula pulmonar estructuralmente normal es aun menos frecuente, de hecho, entre los años 1960 y 1999 fueron sólo 36 los casos publicados en la literatura (5). En estos se identificaron como principales factores de riesgo la adición a drogas por vía parenteral y la presencia de catéteres en arteria pulmonar $(4,5)$. El agente etiológico principal es el Staphylococcus aureus, no obstante se han descrito casos por S. epidermidis, S. lugdunensis, Streptococcus agalactiae, Enterococcus faecalis, enterobacterias, Pseudomonas aeruginosa y levaduras $(1,4-7)$. La endocarditis pulmonar puede cursar con embolismos pulmonares, como presenta este paciente, siendo el pronóstico favorable y, por tanto, equiparable a otros casos de endocarditis derechas $(4,5)$.

La ecografía transesofágica, de elección en el diagnóstico de endocarditis, sobre todo en pacientes con válvula protésica o en caso de sospecha no confirmada mediante ecografía transtorácica, cobra especial importancia en la exploración de la válvula pulmonar, con una sensibilidad en torno al $90 \%$ frente a un $70 \%$ de la ecografía transtorácica (8).
El tratamiento de la endocarditis enterocócica es la combinación de ampicilina o penicilina con gentamicina o estreptomicina. En los casos de resistencia de alto nivel a gentamicina o estreptomicina se puede tratar con la combinación de ampicilina o penicilina con aquel aminoglucósido sensible. Si existe alta resistencia a los dos aminoglucósidos se puede tratar con ampicilina sola en perfusión continua asociada a ceftriaxona durante un periodo prolongado (9). Las indicaciones de la intervención quirúrgica de endocarditis izquierdas son bastante conocidas, si bien sobre cavidades derechas están menos definidas. En caso de fracaso terapéutico de endocarditis pulmonar se han descrito resultados satisfactorios de intervención quirúrgica con valvectomía parcial o total tanto a corto como a largo plazo $(5,10)$.

\section{A. López Jiménez ${ }^{1}$, J. Gallego Plazas, J. M. Ramos Rincón², M. García Martínez}

${ }^{1}$ Secciones de Oncología Médica, ${ }^{2}$ Medicina Interna (Unidad de Enfermedades Infecciosas) y ${ }^{3}$ Cardiología. Hospital General Universitario Elche. Alicante

1. Pérez-Paredes M, Ramos Rincón JM, Carnero Varo A, Giménez Cervantes DM, Blázquez Garrido R, Ruiz-Ros J. Endocarditis pulmonar aislada sobre válvula nativa en un paciente anciano sin factores predisponentes. Rev Esp Cardiol 2001; 54: 402-404.

2. Watanakunakorn $\mathrm{C}$, Burket T. Infective endocarditis at a large community teaching hospital, 1980-1990. A review of 210 episodes. Medicine (Baltimore) 1993; 72: 90-102.

3. Fernández-Guerrero ML, Verdejo C, Azofra J, Górgolas M. Hospitalacquired infections endocarditis not associated with cardiac surgery: an emerging problem. Clin Infect Dis 1995; 20: 16-23.

4. Akram M, Khan IA. Isolated pulmonic valve endocarditis caused by group B streptococcus (Streptococcus agalactiae). A case report and literature review. Angiology 2001; 52: 211-5.

5. Ramadan FB, Beanlands DDS, Burwash IG. Isolated pulmonic valve endocarditis in healthy hearts: Case report and review of literature. Can J Cardiol 2000; 16: 1282-8.

6. Kamaraju S, Nelson K, Williams DN, Ayenew W, Modi KS. Staphylococcus lugdunensis pulmonary valve endocarditis in a patients of chronic hemodialysis. Am J Nephrol 1999; 19: 605-8.

7. Repiso M, Castiello J, Repáraz J, Uriz J, Sola J, Elizondo MJ. Endocarditis por Klebsiellla oxytoca : a propósito de un caso. Enferm Infecc Microbiol Clin 2001; 19: 454-5.

8. Shively BK, Gurule FT, Roldan CA, Leggett JH, Schiller NB. Diagnostic value of transesophageal compared with transthoracic echocardiography in infective endocarditis. J Am Coll Cardiol 1991; 18: 391-397.

9. Mensa J, Gatell JM, Jiménez de Anta MT, Prats G, Domínguez-Gil, eds. Guía Terapéutica antimicrobiana, 12ª ed. Barcelona: Mansson, 2002.

10. Llosa JC, Gosalbez F, Cofino JL, Naya JL, Valle JM. Pulmonary valve endocarditis: mid-term follow up of pulmonary valvectomies. J Heart Valve Dis 2000; 9: 359-63.

\section{Endocarditis bacteriana en un adulto sobre la propia comunicación interventricular congénita}

\section{Sr Director:}

Las manifestaciones cardíacas congénitas en pacientes pediátricos constituyen el mayor riesgo para desarrollar endocarditis bacteriana (1), sin embargo en adultos la endocarditis sucede más frecuentemente sobre valvulopatías reumáticas, degenerativa y sobre prótesis valvulares. A continuación describimos el caso de un adulto con una comunicación interventricular (CIV) congénita que presentó una endocarditis sobre la propia comunicación por Streptococcus sanguis. 
Varón de 21 años con antecedentes personales de CIV detectada en la tercera semana neonatal, decidiéndose tratamiento médico. Vida activa sin ningún tipo de limitaciones no alergias ni hábitos tóxicos. Ergometría con excelente carga funcional. Ecografía cardiaca con cavidades derechas normales y relación flujo pulmonar-flujo sistémico (Qp/Qs) inferior a dos. Desde hace tres meses presenta fiebre diaria de hasta $38,3^{\circ}$ C, sin otra sintomatología acompañante a excepción de dolor pleurítico en base pulmonar izquierda veinticuatro horas previas al ingreso.

Exploración física: tensión arterial 110/60, frecuencia cardiaca $95 \mathrm{lpm}$. Buen estado general, presión venosa yugular normal, ausencia de adenopatías y tiroides normal. Tórax: auscultación cardiaca, soplo en barra V/VI, auscultación pulmonar y abdomen normales. Extremidades normales sin estigmas de endocarditis.

Pruebas complementarias: Analíticas: VSG $32 \mathrm{~mm}$. Hemograma leucocitos $13.200 / \mathrm{mm}^{3}$ con neutrofilia. Coagulación normal. Bioquímica: bilirrubina total $1,33 \mathrm{mg} / \mathrm{dl}$, glucosa, urea, creatinina, ácido úrico, sodio, potasio, cloro, calcio total, fósforo, colesterol total, triglicéridos, GOT, GPT, gamma-GT, fosfatasa alcalina, CPK y proteínas totales normales. Marcadores de lesión miocárdicas (Troponina I y mioglobina) normales. Factor reumatoide $25,1 \mathrm{Ul} / \mathrm{ml}$, proteína $\mathrm{C}$ reactiva $(\mathrm{PCR}) 5,4 \mathrm{mg} / \mathrm{dl}$. LDH 576 U/1. Hierro $35 \mathrm{gr} / \mathrm{dl}$. Ferritina, vitamina B12 y folato normales. Anticuerpos antinucleares negativos. Hormonas tiroideas y orina normal. Serología Rikettsia, virus de Epstein-Barr (VEB), Brucella, anticuerpos no treponémicos (RPR), Echinococcus granulosus, virus de hepatitis B, C y VIH negativos. Serología Clamydia positivo a título bajo con Ig M negativa. Prueba de Mantoux negativa. Baciloscopia en esputo negativa en tres muestras y cultivos de Micobacterias negativos. Hemocultivo positivo a Streptococcus sanguis I.

Radiología de tórax: plétora pulmonar con índice cardiotorácico en el límite y ventrículo derecho normal. Ecografía cardiaca transtorácica: ventrículo izquierdo con CIV multifenestrada restrictiva con dos orificios perimembranosos de unos $4 \mathrm{~mm}$, flujo turbulento y material fibrinoide en cara ventricular derecha, inmóvil, polifásico que se puede corresponder con vegetación. Qp/Qs igual a 2, ventrículo derecho con diámetro límite y con una presión sistólica en torno a $30 \mathrm{~mm}$ de $\mathrm{Hg}$. Resto normal.

Ecocardiografía transesofágica (Fig. 1): Se observa una CIV perimembranosa de $48 \mathrm{~mm}$ con una formación seudoaneurismática en el lado derecho, ocupada por material abscesificado. Ecografía abdominal normal. Fondo de ojo normal.

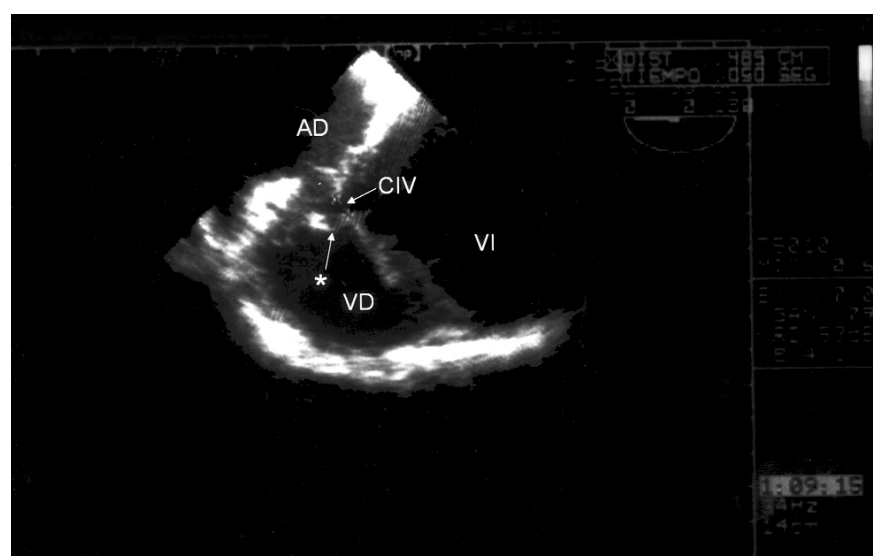

Fig. 1. Ecocardiografía transesofágica en plano de cuatro cámaras con inclinación posterior derecha. Se observa una CIV perimembranosa de $48 \mathrm{~mm}$ con una formación seudoaneurismática en el lado derecho, ocupada por material abscesificado*. AD: aurícula derecha. VD: ventrículo derecho. VI: ventrículo izquierdo. CIV: comunicación interventricular.
Se inició tratamiento con Penicilina y Gentamicina complicándose posteriormente con hepatitis farmacológica. El dolor pleurítico cedió con antiinnflamatorios, comprobándose mediante radiología un infarto pulmonar embólico basal izquierdo con control prácticamente normal al alta. Posteriormente, una vez superado el episodio infeccioso fue sometido a cierre quirúrgico electivo de la CIV. Actualmente se encuentra asintomático y sin tratamiento, siendo la última ecocardiografía normal.

En los pacientes que presentan endocarditis bacteriana, la enfermedad reumática cardiaca junto con la valvulopatía degenerativa y la prótesis valvular constituyen las manifestaciones más comunes $(68 \%)$ como enfermedad subyacente seguido de la enfermedad congénita cardiaca; siendo la regurgitación mitral junto con la aórtica las lesiones valvulares más frecuentes $(47 \%)$ en aquellas con enfermedad reumática cardiaca, mientras que el defecto septal ventricular fue el más común (43\%) en aquellas con enfermedad cardiaca congénita.

La historia natural de la CIV puede oscilar entre el cierre espontáneo, la insuficiencia cardiaca congestiva y muerte en las primeras fases de la lactancia. Pudiendo presentar diversas complicaciones tales como: el desarrollo de obstrucción vascular pulmonar, obstrucción del tracto de salida del ventrículo derecho, incompetencia aórtica y endocarditis infecciosa; esta última su frecuencia varía según diferentes series entre un 10$13 \%(1-2)$.

La CIV suele ser única, situado en la porción membranosa del tabique. La alteración funcional depende principalmente de su tamaño y del estado de la circulación pulmonar, más que de la localización del defecto. La CIV de los adultos sólo se suelen observar los defectos de tamaño pequeño o moderado, ya que la gran mayoría de los pacientes con grandes defectos aislados solicitan atención médica y a menudo quirúrgica a edades muy tempranas (3). Generalmente son asintomáticos en el $77 \%$ de casos (4). El cierre espontáneo varía según las series desde un $10 \%$ hasta un $40 \%$ (2-4) respectivamente en la edad adulta.

Pacientes con defecto ventricular septal pequeño en adultos en un $25 \%$ tuvo serias complicaciones tales como: endocarditis bacterianas $(11 \%)$ antes mencionada, regurgitación aórtica progresiva en un $5 \%$ y arritmias sintomáticas en un $8,5 \%$, siendo la fibrilación auricular la más frecuente; ante lo cual el curso del pequeño defecto ventricular no tiene porque ser necesariamente benigno durante la vida adulta (2).

Los mecanismos por los cuales la manifestación cardiaca congénita predispone a endocarditis bacteriana son la alteración de flujos intracardíacos y producción de turbulencias que ocasionan daño endocárdico y posterior colonización bacteriana.

En la endocarditis sobre CIV las vegetaciones se sitúan en la pared libre del ventrículo derecho o en la valva septal de la válvula tricúspide ya que son los puntos donde choca el chorro del cortocircuito, es menos frecuente que la vegetación se sitúe en la pared de la propia comunicación como ocurrió en nuestro caso (5).

Los pacientes con grandes comunicaciones interventriculares e hipertensión pulmonar son los que presentan un riesgo mayor de desarrollar lesiones obstructivas en la circulación pulmonar. Puede suceder que el proceso de endocarditis infecciosas y defecto septal interventricular se complique con embolismo pulmonar $(6,7)$ como sucedió en este paciente; llevando en algunos casos a la muerte del mismo; de hecho el defecto septal cardíaco junto con la endocarditis bacteriana son los mayores factores de riesgo de desarrollar embolismo séptico pulmonar (8). Los microorganismos responsables, los criterios diagnósticos y los tratamientos de endocarditis sobre manifestación cardiaca congénita no difieren de los establecidos para endocarditis que ocurren sobre otras cardiopatías (5). La ecocardiografía hace posible la identificación y evaluación de las complicaciones asociadas con elevada morbi- 
lidad y mortalidad en pacientes con enfermedad cardiaca congénita y endocarditis infecciosa (3).

A edad joven la mortalidad por endocarditis infecciosa aguda fue del $21 \%$ globalmente, siendo el $50 \%$ de insuficiencia cardiaca congestiva refractaria, $33 \%$ mal control de la sepsis y el $17 \%$ por embolismos. La esperanza de vida de los pacientes con manifestaciones cardíacas congénitas ha mejorado mucho en los últimos años debido a los progresos en tratamiento médico y quirúrgico llegando más pacientes a la edad adulta por lo que es de esperar un aumento en la frecuencia de endocarditis sobre esta población al igual que a ocurrido con la patología valvular degenerativa. El riesgo de endocarditis sobre CIV se duplica si ésta no se corrige mediante cirugía y también aumenta si la CIV se asocia a insuficiencia aórtica, sin embargo no tiene relación con el diámetro del defecto (5).

El defecto ventricular septal aislado precisa corrección quirúrgica en el $15 \%$ del total de casos; según otras series en un $75 \%$ (9) estando indicada la cirugía en los casos de gran shunt izquierda-derecha (QP/QS mayor de 2) y cuando hay complicaciones (3) como sucedió con nuestro paciente; siendo importante el tratamiento quirúrgico completo ya que el cierre quirúrgico reduce el riesgo de endocarditis bacteriana (10). En pacientes sometidos a cirugía paliativa o correctora el riesgo de endocarditis no desaparece mientras persista algún defecto residual o se introduzca material protésico.

Para prevenir la endocarditis en estos pacientes es fundamental la profilaxis antibiótica en todas aquellas situaciones en las que están indicadas. Además en todos aquellos enfermos con una manifestación cardiaca congénita conocida, corregida o no, que presenten fiebre sin focalidad clínica habrá que considerar el diagnóstico de endocarditis.

\section{C. Calleja Subirán, F. Taboada Vilariño,}

Servicio de Medicina Interna y Cardiología ${ }^{I}$. Hospital Nuestra Señora de Sonsoles. Ávila

1. Martin JM, Neches WH, Wald ER. Infective endocarditis: 35 years of experience at childrens hospital. Clin Infect Dis 1997; 24: 669-75.

2. Neumayer U, Stone S, Somerville J. Small ventricular septal defects in adults. Eur Heart J 1998; 19: 1573-82.

3. Chantepie A. Ventricular septal defects in the adult. Arch Mal Coeur Vaiss.2002; 95 (11): 1074-80.

4. Frontera-Izquierdo P, Cabezuelo-Huerta G. Natural and modified history of isolated ventricular septal defect: a 17- year study. Pediatr Cardiol 1992; 13 (4): 193-7.

5. Perello Roso A, Osa Sáez A, García Casco MP, Mico Giner ML. Bacterial endocarditis in an adult with ventricular septal defect. An Med Interna (Madrid) 2001; 18: 396-7.

6. Zijlstra F, Fioretti P, Roelandt JR. Echocardiographic demonstration of free wall vegetative endocarditis complicated by a pulmonary embolism in a patient with ventricular septal defect. Br Heart J 1986; 55: 497-9.

7. Hirotani T, Kiso I, Tsurumi T, Umezu Y, Shin H. A case of pulmonary infarction secondary to subcaute bacterial endocarditis with subpulmonary VSD. Kyobu Geka 1989; 42 (3): 236-8.

8. Taniguchi H, Fujisaka S, Abo H, Miyazawa H, Noto H. Pulmonary septic emboli in a patient with rigth-side infectious endocarditis. Nihon Kokyuki Gakkai Zasshi 2003; 41 (9): 666-70.

9. Tanaka S, Hachida M, Kitamura M, Ohtsuka G, Shimamu D, Nishida $\mathrm{H}$ et al. Surgical treatment of infective endocarditis in patient with congenital heart disease.Nippon Kyobu Geka Gakkai Zasshi 1994; 42: 1032-7.

10. Gersony WM, Hayes CJ, Driscoll DJ, Keane JF, Kidd L, O’Fallon WM et al. Bacterial endocarditis in patients with aortic stenosis, pulmonary stenosis, or ventricular septal defect. Circulation 1993; 87 (Supl. 2): 1121-6.

\section{Autotratamiento de la insuficiencia suprarenal de origen hipofisario}

\section{Sr. Director:}

En medicina tendemos a justificar los síntomas y signos que presenta un paciente como secundarios a procesos que padecen de forma evidente. Esto no siempre es así. Presentamos un caso que ilustra esta afirmación.

Varón, 87 años. No hábitos tóxicos. Heridas de metralla en cráneo durante su juventud. Asma en tratamiento ocasional con broncodilatadores inhalados y corticoides orales, que llegaba a tomar durante semanas en las reagudizaciones. Ingresa por presentar desde hace un mes deterioro progresivo de su estado general acompañado de vómitos postprandiales, astenia, anorexia y pérdida de $6 \mathrm{Kg}$, que el paciente justificaba por la disminución de la ingesta y los vómitos. A lo largo de su vida refería episodios similares "que cedían de forma espontánea". No presentaba ninguna otra sintomatología en el interrogatorio por órganos y aparatos. Exploración: Consciente, orientado, normocoloreado. CC: sin hallazgos. Auscultación cardiopulmonar: normal. Abdomen y extremidades: normales. TA 110/70 mmHg. FC: 70 latidos por minuto. Hb: 10.5 gr/dl. Hto: 29\%. VCM: 82,8 fl. HCM: 28,2 g/dl. Leucocitos: 4870 x 1.000/ $\mu \mathrm{L}$ (2.680 Neutrófilos, 1090 linfocitos, 550 eosinófilos). Plaquetas: $328 \times 1000 / \mu \mathrm{L}$. Glucosa $74 \mathrm{mg} / \mathrm{dl}$. LDH: 112 UI/L. GOT: 30 UI/L. GPT: 24 UI/L. GGT: 12 UI/L. FA: $103 \mathrm{UI} / \mathrm{L}$. Bt: 0,36 mg/dl. Proteínas $5 \mathrm{gr} / \mathrm{dl}$. Albúmina 2,81 $\mathrm{g} / \mathrm{dl}$. Cr: $0,71 \mathrm{~g} / \mathrm{dl}$. Calcio: $8,1 \mathrm{mg} / \mathrm{dl}$. Fósforo: $2,6 \mathrm{mg} / \mathrm{dl}$. ürico 2,4 mg/dl. Colesterol $141 \mathrm{mg} / 100$. Triglicéridos: $108 \mathrm{mg} / 100$. Sodio $118 \mathrm{meq} / 1$. Potasio 4,6 meq/l. Sodio en orina: 114,6 meq/1. Potasio en orina 4,1 meq/l. Osmolaridad en sangre 256 miliosmoles. Osmolaridad en orina: 260 miliosmoles. CEA: 2,1 $\mu \mathrm{g} / \mathrm{ml}$. Ca72.4: 1,6 UI/ml. Alfafetoproteina: 0,2 UI/ml. T4 libre: 0,9 $\mu \mathrm{g} / \mathrm{dl}$. (N: 0,7-1,8) TSH: $1,7 \mu \mathrm{UI} / \mathrm{ml}(\mathrm{N}: 0,5-5)$. FSH $1,2 \mathrm{mUI} / \mathrm{ml}$ (N: 1,5-12,4). LH: 0,6 mUI/ml (N: 1,7-8,6). Testosterona: < 2,00 $\mathrm{ng} / \%$ (N 280-800). Prolactina 10,3 ng/ml. (N: 0-20). IGF-1: $<25$. GH: $0,08 \mathrm{ng} / \mathrm{ml}(\mathrm{N}: 0,00-5,00)$ Cortisol basal: 3,9 $\mu \mathrm{g} \%(\mathrm{~N}: 7-25)$. Cortisol en orina: $3 \mu \mathrm{g} / 24 \mathrm{~h}$ (N 26-135). ACTH basal: $7 \mathrm{pg} / \mathrm{ml}$ (N: 9-52) Cortisol postACTH: $12,8 \mu \mathrm{g} / \%$.

Gastroscopia: esófago de Barret de segmento largo. Hernia de hiato. Rx tórax: Importante hernia hiatal. Estudio gastroduodenal: Importante hernia de hiato. TAC toracoacoabdominal: Gran hernia de hiato deslizante. Resto normal. TAC craneal: Masa en silla turca que mide $2 \times 2 \times 2 \mathrm{~cm}$ redondeada y bien delimitada que capta contraste homogéneamente y agranda la silla turca ocupando la cisterna suprasellar, compatible con adenoma hipofisario. Cuerpos extraños metálicos en región retrosilviana izquierda y prerolándica derecha. RMN craneal: no realizada por el antecedente de herida de metralla intracraneal confirmada en el TAC. Interconsulta a neurocirugía: se desestima cirugía en base a la edad del paciente y localización de la lesión. Se comenzó tratamiento con hidroaltersona, quedando el paciente asintomático con niveles de sodio normales.

Los vómitos pueden ser la manifestación de una amplia gama de enfermedades en relación con procesos digestivos o extradigestivos. En ocasiones pueden tener consecuencias que pongan en peligro la vida del paciente tales como aspiración o alteraciones hidroelectrolíticas graves (1). El hipopituitarismo es una insuficiencia hipofisaria de etiología múltiple que puede afectar a una o varias hormonas (2). Su causa más frecuente es el adenoma hipofisario y si éste se diagnostica es necesario conocer si es o no funcionante, ya que tiene implicaciones en cuanto al tratamiento (3). La clínica del hipopituitarismo puede ser muy variable y depende de las hormonas hipofisarias comprometidas, de si el déficit es total o parcial, de la edad del paciente y de si la causa es hipotalámica o hipofisaria. Es preci- 
so disponer de determinaciones hormonales basales y pruebas dinámicas del eje hipotálamo-hipofisario, así como de estudios de imagen, siendo la RMN la prueba más sensible y específica para el estudio de la silla turca $(4,5)$. El déficit de ACTH condiciona un cuadro de insuficiencia suprarenal con astenia, anorexia, vómitos, pérdida de peso e hipotensión. Cuando es secundaria no aparece hipopotasemia ni hiperpigmentación. Analíticamente es típica la eosinofilia en sangre periférica. El paciente fue ingresado para estudio de síndrome constitucional, vómitos e hiponatremia severa sintomática. La sospecha primaria fue un proceso maligno probablemente digestivo. Ante la negatividad del estudio y a pesar de una causa (hernia de hiato gigante), que justificaba los vómitos y secundariamente la hiponatremia, se realizó despistaje de insuficiencia suprarenal confirmándose bioquímicamente su origen hipofisario (Cortisol basal bajo, ACTH basal bajo) en relación con un adenoma hipofisario que también producía déficit de hormonas sexuales. Probablemente la toma intermitente de prednisona por su asma, enmascaró durante años los síntomas de su enfermedad al tratar al menos parcialmente, el déficit de cortisol, demorando el diagnóstico. Ante la presencia de un cuadro de vómitos, síndrome constitucional e hiponatremia es necesario tener en mente, a pesar de la existencia de procesos que lo justifiquen, la existencia de una insuficiencia suprarenal, en este caso secundaria, enfermedad que aunque grave, es subsidiaria de tratamiento. Destacar que no siempre en medicina lo evidente es lo que justifica los síntomas a los que nos enfrentamos, por lo que es preciso tener un elevado índice de sospecha, ya que un mismo síntoma o signo puede ser causado por varios procesos simultáneos.

\section{F. J. Sánchez Ayuso, E. Jódar ${ }^{1}$}

Servicio de Medicina Interna y de 'Endocrinología. Hospital Universitario 12 de Octubre. Madrid

1. Hanson JS, McCallum RW. The diagnosis and management of nausea and vomiting: a review. Am J Gastroenterol 1985; 80 (3): 210-218.

2. Herrera Pombo JL. Panhipopituitarismos. Medicine 2000; 8 (16): 855859.

3. Simón I, Melmed S. Management of pituitary tumors. Ann Intern Med 1998; 129: 472-483.

4. Casanueva F. Panhipopituitarismos. En: Farreras-Rozman eds. Medicina Interna. Edit. Hartcourt, 2000; 2: 2306-2308.

5. Streeten DH. What test for hipothalamic-pituitary-adrenal insufficiency. Lancet 1999; 354: 179.

6. Gordon H, Dluhi R. En Harrison's eds. Principles of Internal Medicine. McGraw-Hil, 2001; 2084-2105. 